\title{
Regular physical exercise training assists in preventing type 2 diabetes development: focus on its antioxidant and anti-inflammatory properties
}

\author{
Edite Teixeira-Lemos, Sara Nunes, Frederico Teixeira, Flávio Reis ${ }^{*}$
}

\begin{abstract}
Diabetes mellitus has emerged as one of the main alarms to human health in the 21st century. Pronounced changes in the human environment, behavior and lifestyle have accompanied globalization, which resulted in escalating rates of both obesity and diabetes, already described as diabesity. This pandemic causes deterioration of life quality with high socio-economic costs, particularly due to premature morbidity and mortality. To avoid late complications of type 2 diabetes and related costs, primary prevention and early treatment are therefore necessary. In this context, effective non-pharmacological measures, such as regular physical activity, are imperative to avoid complications, as well as polymedication, which is associated with serious side-effects and drug-to-drug interactions.

Our previous work showed, in an animal model of obese type 2 diabetes, the Zucker Diabetic Fatty (ZDF) rat, that regular and moderate intensity physical exercise (training) is able, per se, to attenuate insulin resistance and control glycaemia, dyslipidaemia and blood pressure, thus reducing cardiovascular risk, by interfering with the pathophysiological mechanisms at different levels, including oxidative stress and low-grade inflammation, which are key features of diabesity.

This paper briefly reviews the wide pathophysiological pathways associated with Type 2 diabetes and then discusses in detail the benefits of training therapy on glycaemic control and on cardiovascular risk profile in Type 2 diabetes, focusing particularly on antioxidant and anti-inflammatory properties. Based on the current knowledge, including our own findings using an animal model, it is concluded that regular and moderate intensity physical exercise (training), due to its pleiotropic effects, could replace, or at least reduce, the use of anti-diabetic drugs, as well as of other drugs given for the control of cardiovascular risk factors in obese type 2 diabetic patients, working as a physiological "polypill".
\end{abstract}

\section{Introduction}

Type 2 diabetes mellitus (T2DM) achieved proportions of a real epidemic and, according to the International Diabetes Federation (IDF), the disease now affects 246 million people worldwide and is expected to affect about 380 million by 2025 [1]. This panorama is even more dramatic if considered that over the past 20 years its prevalence has increased dramatically among children and adolescents. As such, the incidence/prevalence of

\footnotetext{
* Correspondence: freis@fmed.uc.pt

Unit of Therapeutics, Laboratory of Pharmacology and Experimental Therapeutics, IBILI, Medicine Faculty, University of Coimbra, Portugal
}

serious diabetic complications (which includes cardiovascular disease, kidney failure, blindness and amputations) as well as the premature death, will unequivocally deteriorate life quality and exacerbate health costs, unless more effective primary and secondary pharmacological and non-pharmacological (lifestyle interventional) strategies become more widely available and implemented. The therapeutic arsenal now available to manage T2DM has proved inefficacy to prevent the rise in incidence of cardiovascular events, the leading cause of morbidity and early mortality of diabetic patients. The improvement of cardiovascular profile will depend not 
only on the reduction of glycosylated hemoglobin (HbA1c) levels, but also of other factors, such as blood pressure. The Steno-2 study [2] clearly demonstrated that only intensive multifactorial intervention, involving pharmacological measures and lifestyle modifications, could promotes sustained beneficial effects on rates of death and cardiovascular disorders in T2DM patients.

Several prospective studies have associated time spent in sedentary activities, such as TV watching and computer or video-games use, with increasing obesity [3] and T2DM development [4]. Thus, the low level of physical activity (sedentarism) has been considered a risk factor for early mortality, in parallel with smoking habits, arterial hypertension and dyslipidaemia. The regular practice of moderate intensity physical exercise (training) showed capacity to reduce body weight, improve insulin sensitivity, increase circulating levels of highdensity lipoprotein (HDL), decrease triglyceride levels and normalize blood pressure $[5,6]$.

This paper will review the effects of regular practice of an aerobic exercise program of moderate intensity (training) in the prevention of T2DM or attenuation of its progression, based on the present literature as well as on our knowledge using an experimental model of obese T2DM. We will firstly focus on the effects at different risk factors related to insulin resistance (IR) and glucose intolerance stages, which precedes the onset of sustained T2DM; thereafter, the review will focused on the effects promoted by exercise training on oxidative stress and low-grade inflammation, which play a key role on the onset and progression of diabetes.

\section{Natural history of T2DM: role of oxidative stress and inflammation}

T2DM is a complex heterogeneous group of metabolic conditions characterized by increased levels of blood glucose due to impaired insulin action and/or secretion [7]. Physiologically, the pancreatic $\beta$-cells constantly synthesize insulin, regardless of blood glucose levels. Insulin is stored within vacuoles and released once triggered by an elevation of the blood glucose level. Insulin is the key hormone concerning the regulation of glucose uptake from blood into most cells, including skeletal muscle cells and adipocytes. Insulin is also the major signal for conversion of glucose to glycogen for internal storage in liver and skeletal muscle cells. A drop in the blood glucose level results in decrease of insulin release from $\beta$-cells and in increase of glucagon release from $\alpha$-cells, which stimulates glycogen to glucose conversion. Following an overnight fast, glucose is largely produced by glycogenolysis and gluconeogenesis.

There are three key defects in the onset of hyperglycemia in T2DM: increased hepatic glucose production, diminished insulin secretion and impaired insulin action
[8]. Insulin resistance refers to a suppressed or delayed response to insulin and is generally a post-receptor phenomenon, due to a defect in cells that respond to insulin, rather than on insulin production.

Insulin resistance in muscle and liver, together with $\beta$ cell failure, are pivotal pathophysiologic defects in T2DM. It is now recognized that $\beta$-cell failure occurs much earlier and is more severe than previously thought. Subjects in the upper tertile of impaired glucose tolerance (IGT) are maximally or near-maximally insulin resistant and have lost over $80 \%$ of their $\beta$-cell function. In addition to muscle, liver and $\beta$-cells, the fat cell (accelerated lipolysis), the gastrointestinal tract (incretin deficiency/resistance), the $\alpha$-cell (hyperglucagonemia), the kidney (increased glucose reabsorption) and the brain (insulin resistance) all play important roles in the development of glucose intolerance in type 2 diabetic individuals.

The insulin resistance observed in obese T2DM patients is secondary to changes in insulin receptors signal transduction, arising from genetic and/or environmental factors, such as excessive caloric consumption, sedentary lifestyle and obesity [9]. T2DM emerges when these change are associated with a progressive decrease in the secretory capacity of pancreatic beta cells (relative insulinopenia). It is a silent disease, in which the loss of secretory capacity begins years before the clinical diagnosis. In the phase of insulin resistance, glucose intolerance or glycaemia rise may occur in the unfed state. As long as the $\beta$-cells are able to augment insulin secretion to compensate insulin resistance, glucose tolerance remains normal. However, with time, the $\beta$-cells begin to fail and the postprandial plasma glucose levels (initially) and the fasting plasma glucose concentration (subsequently) begin to rise, leading to the onset of overt diabetes $[9,10]$.

It has been suggested that chronic hyperglycaemia or even the intermittent blood glucose elevations observed in patients with apparent acceptable glycaemic control may contribute to the development of macro and/or microvascular complications $[11,12]$. However, many different pathophysiological pathways may be simultaneously activated, which includes oxidative stress and low-grade inflammation.

\section{Role of oxidative stress in the progression of T2DM}

It has been shown that reactive oxygen species (ROS) are produced in various tissues under diabetic conditions, by the several mechanisms, such as non-enzymatic glycosylation reactions, electron transport chain in the mitochondria and membrane-bound nicotinamide adenine dinucleotide phosphate (NADPH) oxidase [13]. Several lines of evidence support a close association between oxidative stress and diabetes evolution, 
revealing that oxidative stress secondary to hyperglycaemia and hyperlipidaemia occurs before the appearance of clinical manifestations of late diabetes complications, suggesting a key role in the pathogenesis of the disease. Therefore, insulin resistance and pancreatic $\beta$-cell dysfunction, which are hallmarks of type 2 diabetes, are modulated by ROS [14-16]. Under diabetic condition, chronic hyperglycaemia may induce large amounts of ROS that are responsible for the progressive dysfunction of $\beta$ cells, worsening insulin resistance and further promoting relative insulin deficiency ROS [17]. It was previously reported that ROS disrupt insulin-induced cellular redistribution of insulin receptor substrate-1 (IRS-1) and phosphatidylinositol 3kinase (PI3K), thus impairing insulin-induced glucose transporter type 4 (GLUT4) translocation in 3T3-L1 adipocytes [14]. The increase of intracellular free fatty acids (FFA), in turn, leads to a decreased translocation of the glucose transporter subtype 4 (GLUT4) to the plasma membrane, leading to insulin resistance in muscle and adipose tissue [18]. In this context, insulin resistance may be considered a compensatory mechanism that protects the cells against further insulinstimulated glucose and fatty acid uptake and, therefore, oxidative damage. Many studies have previously suggested that $ß$-cell dysfunction results from prolonged exposure to high glucose and FFA levels, or a combination of both $[14,15]$. Beta cells, in particular, are particularly sensitive to ROS because they are low in free-radical quenching (antioxidant) enzymes such as catalase, glutathione peroxidase, and superoxide dismutase $[19,20]$. The ROS formed will also indirectly damage cells by activating a variety of stress-sensitive intracellular signaling pathways, including Nuclear factor-kB (NF-kB), mitogen-activated protein kinase p38 (p38MAPK), kinases JunNH2- terminal/kinases of proteins activated by stress (JNK/SAPK), hexosamines, protein kinase $C$ (PKC) and polyol pathway $[15,21,22]$. The activation of these cellular signaling cascades is linked not only with the development of diabetic complications but also with the insulin resistance and pancreatic $\beta$ cell dysfunction. Among the signaling cascades, the NF-kB pathway plays a central role as intermediary of immune and inflammatory responses. This nuclear factor is responsible for regulating the expression of a large number of genes, including those related to diabetes complications, such as the vascular endothelial growth factor (VEGF) [20]. Being an intracellular signaling pathway target of hyperglycaemia and ROS, its activation may also be induced by endogenous and exogenous stimuli, in addition to those above mentioned, such as excess of FFA, tumour necrosis factor $\alpha(\mathrm{TNF}-\alpha)$, interleukin $1 \beta$ (IL-1 $\beta)$ and other pro-inflammatory cytokines, advanced glycation endproducts (AGE) related to receptor for $A G E$ (RAGE), p38MAPK, DNA damage, viral infection and ultraviolet radiation [21].

\section{Role of inflammation in the progression of T2DM}

Obesity, as a result of inactivity in combination with overeating, plays a key role in the development of pancreatic beta-cell dysfunction and in insulin resistance. An increased mass of stored triglycerides (TGs), especially in visceral or deep subcutaneous adipose stores, leads to large adipocytes, that are resistant to insulinevoked lipolysis suppression, resulting in increased release of FFA and glycerol. This "dyslipidaemic phenotype of diabetes", characterized by increased content of TGs and oxidized low density lipoproteins (ox-LDL), together with decreased levels of HDL, is responsible for the lipotoxicity profile of diabetes. Lipotoxicity has been used to describe the deleterious effect of tissue fat accumulation on glucose metabolism and includes the notion that increased plasma FFA/intramyocellular levels of toxic lipid metabolites (such as long-chain fatty acyl CoAs, diacylglycerol and ceramides) play a role in the pathogenesis of muscle/liver insulin resistance.

In addition, fat cells produce adipocytokines, which go through distant sites (such as muscle, liver and arterial tissue), where exert deleterious effects on metabolism and vascular function. Adipose tissue of obese and type 2 diabetic individuals is infiltrated by mononuclear cells and is in a state of chronic inflammation [23]. The adipocytes and infiltrated macrophages secrete pro-inflammatory/pro-thrombotic cytokines, such as the TNF- $\alpha$, interleukin-6 (IL-6), resistin, adipsin, acylation-stimulating protein (ASP), plasminogen activator inhibitor 1 (PAI-1) and angiotensinogen, that promote atherogenesis and cause insulin resistance. Adipocytes also produce adiponectin, a potent insulin-sensitizing and anti-atherogenic cytokine, now included in a vast group of substances named adipokines or adipocytokines. Low adiponectin levels have been correlated with visceral obesity and whole-body insulin sensitivity [24]. This fat cell hormone acts as an insulin sensitizer, inhibiting TGs formation in liver and stimulating fatty acid oxidation in muscle in an 5' adenosine monophosphate-activated protein kinase (AMPK) and peroxisome proliferators activated receptor alpha (PPAR- $\alpha$ )-dependent manner [25]. Despite their apparent importance in the insulin resistance syndrome, aforementioned adipokines are just examples of a family of adipocyte-derived factors that modulate insulin resistance and systemic inflammation. Besides new adipokines, also certain myokines now appear to affect insulin sensitivity and inflammatory responses. As such, the list of insulin (de)sensitizing proteins and cytokines is still far from complete. 
The secretion of citokines depends not only on the amount of adipose tissue but also of its location, being visceral or intra-abdominal fat more harmful than subcutaneous fat. The pro-inflammatory effects of cytokines are felt at the intracellular levels of signaling cascades and involves the pathways of $\mathrm{NF}-\kappa \mathrm{B}$ and JNKs [26,27].

The increase of pro-inflammatory cytokines, associated with the dyslipidaemic profile in T2DM, may not only modulate the function of pancreatic beta cells but also their survival. Several studies showed that exposure of $\beta$ cells to high levels of saturated fatty acids and lipoproteins undertake to their death, and this effect is accelerated by hyperglycaemia, demonstrating that lipotoxicity and glucotoxicity, in concert, determinate beta-cell failure [28-31].

The briefly preceding review of the key pathophysiological mechanisms of T2DM highlights several relevant aspects for the therapeutics. First, effective treatment of T2DM will require combination of multiple drugs to correct the various pathophysiological defects. Second, treatment should not be simply directed to HbA1c reduction, but also based upon known pathogenic abnormalities, which includes the preservation of antioxidant and anti-inflammatory capacity. Third, since progressive $\beta$-cell failure is to be prevented, therapy must be started early in the natural history of type 2 diabetes.

\section{Exercise training as a therapeutic modality in T2DM}

Physical inactivity has been identified as a stronger predictor of chronic diseases even when compared with traditional risk factors, such as hypertension, hyperlipidaemia, diabetes and obesity. Moreover, regular physical activity appears to protect against premature death, independently of obesity.

Several studies, clinical and experimental, have been assessing the role of regular physical activity (training) on cardiovascular and cardiometabolic disorders, including on diabetes. Although results from studies using animals cannot be directly extrapolated for humans, animal models of T2DM could offer excellent opportunities to evaluate experimental conditions and to assess tissues that cannot be tested in humans, thus improving the knowledge about the endocrine, metabolic and morphological changes underlying the pathogenic mechanisms of the disease and the treatment options.

In the following topics we will review the benefits of a particular physical exercise (training) in the wide pathophysiological aspects associated with T2DM, focusing on antioxidant and anti-inflammatory properties, based on the information already available in the literature, from both clinical and experimental studies, and in particular on the data obtained from our own experiments using an animal model of obese T2DM, the Zucker Diabetic Fatty (ZDF $f a / f a)$ rats.

In order to not repeat the information alongside the text, the physical exercise program performed by us, which will be mentioned during the review, was a regular and moderate intensity aerobic exercise (defined as training), consisting of 12 weeks ( $1 \mathrm{~h} /$ day, 3 times/week) of swimming program, voluntary, for both the male obese diabetic rats (ZDF $f a / f a)$ and the male control lean animals (ZDF $+/+$ ), between 8 and 20 weeks of age [32-34]. In brief, the protocol used was: the animals, maintained under controlled temperature $\left(22^{\circ} \mathrm{C}\right)$, humidity $(60 \%)$ and lighting ( $12 \mathrm{~h}$ of light) conditions, given a rodent maintenance chow (A-04 Panlab, Barcelona, Spain) adjusted to their respective weights $(100 \mathrm{mg} / \mathrm{g}$ of weight) and distilled water ad libitum, perform their exercise in a cylindrical tank, $120 \mathrm{~cm}$ in diameter and $80 \mathrm{~cm}$ in height, containing water with a controlled temperature $\left(30-32^{\circ} \mathrm{C}\right)$; the animals were placed in the tank every day at the same hour (09.00 -10.00 h) under the supervision of the same person; the swimming period was initially for $15 \mathrm{~min} / \mathrm{d}$ and was gradually increased such that the rats were able to perform exercise for $60 \mathrm{~min} / \mathrm{d}$, which was achieved in $1 \mathrm{wk}$; after $1 \mathrm{wk}$ of this training period, the rats were made to swim for $1 \mathrm{~h}$, three times a week; at the end of each exercise session, the animals were dried and kept in a warm environment; the sedentary rats were kept in the container where the swimming sessions were held for a period of $60 \mathrm{~min}$ to ensure that these control rats underwent the same amount of stress as the test animals that performed exercise. The animals that practiced exercise were sacrificed $48 \mathrm{~h}$ after the end of the last training session to minimize the acute effects of the exercise. The night before sacrifice, food was removed from the animal cages.

\section{Physical activity, obesity and body fat distribution}

Our studies showed that exercised diabetic rats presented, when sacrificed $48 \mathrm{~h}$ after the last bout training session, a trend to increase body weight, which might be due to an increase in muscle mass [34]. Despite the lack of measurement of the animal body fat amount, a reduction in total visceral or subcutaneous fat in exercised animals cannot be excluded. Similar effect was observed by other studies in humans, confirming that after the training there was an increase in muscle mass with decrease in fat mass $[35,36]$.

In the same work, Teixeira de Lemos et al. [34] showed that the weight of some organs or tissues (heart, liver, kidneys and muscle) were heavier in the exercised diabetic rats when compared with the sedentary animals, thus confirming that training leads to important morphological and physiological adaptations to maintain 
body homeostasis, as previously suggested by others $[37,38]$. In addition, the results suggest that the maintenance in time of training is an important factor for the appearance of those adaptations.

The study conducted by Tuomilehto et al. (2001) provided evidence that T2DM, in both women and man at high cardiovascular risk, can be prevented by lifestyles modifications, with a decrease of overall incidence of diabetes of 58\% [39]. Regarding physical exercise practice, which has included components designed to improve both cardiorespiratory fitness and muscle strength, the results showed that more than $4 \mathrm{~h} /$ week of exercise was associated with a significant reduction in risk of diabetes even without weight loss [39]. Some of the key beneficial effects of an exercise program include visceral obesity reduction and muscle mass increase. Randomized control trials conducted in individuals with normal body mass index (BMI), as well as in patients with abdominal obesity and T2DM, demonstrated that physical exercise regularly practiced contributes to diminish total, visceral and subcutaneous fat, even without weight loss, together with improvement of glycaemia and with increase of FFA oxidation and, thus, to an amelioration of the diabetes [40-42].

\section{Physical exercise and glycaemia and insulinaemia control}

The first aim of T2DM treatment is hyperglycaemia control, as a way of reducing chronic diabetic complications, namely of cardiovascular nature. The American Diabetes Association (ADA) recommends a value of $\mathrm{HbA} 1 \mathrm{c}$ above $7 \%$. Our group demonstrated, using the training protocol above described in ZDF $(f a / f a)$ rats, that hyperglycaemia was prevented by exercise, together with a significantly lower value of $\mathrm{HbA} 1 \mathrm{c}$ $(-6,6 \%)$, when compared to sedentary counterpart, reinforcing the idea of a effect maintained over time $[33,34]$. This results were corroborated by Kyraly et al. (2008) in ZDF rats submitted to forced swim training ( $1 \mathrm{~h}$ /day; 5 days/week during 13 weeks) [43]. Additionally, in our study the hiperinsulinaemia was partially, but significantly, corrected in the trained rats, which was accompanied by reduction of insulin resistance, given by the lower HOMA (homeostasis model assessment), and index of insulin resistance. Thu, we hypothesize that swimming training was able to improve peripheral insulin resistance, although the less action on hepatic resistance, suggesting that hyperinsulinaemia could be a reflex of insulin resistance in the liver, not improved by exercise [33,34].

Concerning studies in humans, in a meta-analysis which reviewed the studies concerning exercise intervention of at least 8 weeks in type 2 diabetic individuals, regular aerobic exercise showed a statistically and clinically significant effect on HbA1c, suggesting that this non-pharmacological intervention improve glycaemic control, while having little effect on body weight [44]. Similar results were encountered in another meta-analysis on the effect of exercise practice, which included 14 studies (12 with aerobic exercise and 2 with resistance exercise) [45], demonstrating that the effect of exercise on HbA1c (the major marker of glycemic control), is a well established finding.

The amelioration on glucose metabolism by exercise training may occur primarily through three distinct mechanisms: i) stimulation of glucose transport to muscle; ii) increased in insulin action on cells of the organs involved in the exercise; iii) positive regulation of signaling pathway stimulated by insulin as a result of regular exercise.

Exercise has been indicated as an "insulin-like" activity because of the increase of muscle's capacity to capture circulating glucose, due to decreased intramuscular fat reserves [40]. Christ-Roberts et al. (2004) found that exercise training significantly increased expression of GLUT4 glucose transporter in overweight nondiabetic and diabetic subjects, by $38 \%$ and $22 \%$, respectively $[46,47]$. Akt protein expression, which was decreased by about $29 \%$ in the diabetic subjects before training, when compared to the nondiabetics, increased significantly in both groups [46]. Furthermore, it was also observed that in skeletal muscle exercise training affects the transcriptional regulation of the gene of the IRS-1 and the posttranscriptional regulation of the PI3-kinase expression $[48,49]$. The increased capacity of the muscle to oxidize fat in response to aerobic exercise is also a major mechanism by which exercise training improves insulin sensitivity in the muscle [50]. Taken together, the above mentioned actions of exercise (training) on skeletal muscle contribute to regulate blood glucose levels.

\section{Exercise and dyslipidaemia}

Chronic exercise (training) has favorable effects on lipid profile [34,51], being nowadays viewed as one of the best non-pharmacological strategies for the prevention or attenuation of diabetic dyslipidaemia. Our group demonstrated that aerobic exercise training improved dyslipidaemia in ZDF rats, namely by reducing the totalcholesterol (T-Chol) and triglycerides (TGs) [34]. Among other benefits, exercise stimulates lipolytic activity (with decreased plasma TG), promotes the use of FFA as an energy source and increases HDL concentration. Furthermore, favorable changes in the quantity and composition of LDL particles were also shown, as well as on the quality of HDL $[52,53]$. The primary mediator mechanism of these changes seems to be the beneficial influence of regular exercise on the activity of peripheral enzymes, such as lipoprotein lipase (LPL), lecithin-cholesterol acyltransferase (LCAT) and hepatic lipase (HL) 
[51]. In addition to the regulation of the mechanism of hepatic lipid transformation, moderate physical exercise increases the oxidative capacity of several tissues, including the skeletal muscle, which is under low oxidative capacity in situations of insulin resistance. Physical exercise increases the number of capillaries and oxidative fibers in muscle, increasing lipolysis, which allows free flow of fatty acid to the tissue, reducing its concentration in plasma, which is an indicator of its uptake and oxidation by tissues [54].

It seems clear now that regular exercise training is able to improve lipid metabolism. But is this evident in human studies? Type 2 diabetes populations have been shown to improve fasting blood lipid profile following long-term exercise interventions, with or without dietary restriction $[55,56]$. Furthermore, exercise practice in Type 2 diabetes patients showed improved glycemic control, body composition, blood pressure, muscle strength, and workload capacity, together with attenuated progressive increase in exogenous insulin requirements [57]. In accordance with earlier reports, the randomized trial conducted by Sigal et al. (2007) showed that, despite an unaltered body weight, combined endurance and resistance type of exercise training is able to induce regional changes in fat and lean muscle mass in obese T2DM patients [58]. Furthermore, Lira et al. (2007) also reported that low and moderate exercise intensities (training) appear to promote clear benefits on lipid profile [59].

The exercise is also able to activate an alternative pathway: the AMPK [60]. This enzyme acts on the liver, muscle and adipocytes by increasing fatty acid oxidation, decreasing cholesterol synthesis, lipogenesis and lipolysis, and even modulating insulin secretion on pancreatic islets [61]. Apart from the effect that AMPK appears to have on lipid oxidation, it also plays an important role in decreasing the glucose levels, being able to stimulate GLUT-4 increment [62].

Considering the data above mentioned, it seems obvious that the regular practice of an exercise program has a positive effect on the dyslipidaemic profile displayed by patients with T2DM whic could not be neglected.

\section{Physical exercise and blood pressure}

It is widely accepted that the exercise practiced on a regular basis has an antihypertensive effect in humans $[63,64]$. Indeed, regular exercise (training) is able to reduce heart rate, improving the sensitivity of aortic baroreceptors, which contributes to a more efficient regulation of blood pressure [65]. The beneficial effects on hypertension (blood pressure lowering, either systolic or diastolic) due to decreased activity of both the sympathetic nervous system and the renin-angiotensin system was also documented. Other mechanisms responsible for the antihypertensive effect of training include the decrease in peripheral arterial resistance caused by vasodilatation [66]. Besides improving glycaemic control, a meta-analysis showed that structured exercise intervention studies in non-insulin-dependent Type 2 diabetes patients reduce systolic blood pressure of about -4.16 $\mathrm{mmHg}$ [67]. Such reduction in mean blood pressure are clinically relevant and similar to the effects produced by combined therapy of an angiotensin-converting enzyme (ACE) inhibitor and an thiazide diuretic [68].

Also in animals, as shown by our studies using the ZDF rats as model of type 2 diabetes, training (swimming) has promoted a decrease in systolic and mean blood pressure and in heart rate, together with a diminishment of differential pressure $[33,34]$, suggesting an improvement of vascular arterial compliance, with reduction in cardiac work and a left ventricular hypertrophy amelioration. The increased arterial stiffness appears to be one of the factors that best combine cardiovascular risk and atherosclerosis. Differential pressure has been indicated as an indirect measure of arterial stiffness and a better predictor of coronary risk. By preventing the increasing of differential pressure regular exercise training positively influence the cardiovascular diabetic complications, such as diabetic ischemic heart disease, which is often asymptomatic.

\section{Exercise (training), oxidative stress and T2DM} Exercise and oxidative stress - pathophysiological aspects Exercise is associated with increased formation of free radicals, mainly due to increased $\mathrm{O} 2$ consumption by active tissues. Several studies have shown that the amount of free radicals in biological tissues is increased after acute and/or chronic exercise, which coincides with the presence of tissue damage [69]. Most of the O2 consumed is used in the mitochondria for oxidative phosphorylation, where it is reduced to water. However, a small but significant fraction of $\mathrm{O} 2$ consumed may leave the electron transport chain to produce ROS; it is estimated that approximately $2-5 \%$ of oxygen used by mitochondria are converted into free radicals [70].

Chronic exercise of moderate intensity (training) positively alters the oxidative homeostasis of cells and tissues, by decreasing the basal levels of oxidative damage and increasing resistance to oxidative stress [71]. In fact, regular exercise causes adaptations in the antioxidant capacity, protecting cells against the harmful effects of oxidative stress, thus preventing cellular damage [72,73]. Adaptation to oxidative stress in trained individuals is clearly evidenced by a decrease in DNA damage, by sustained levels of protein oxidation and by an increment of resistance against chronic administration of hydrogen peroxide [74]. Training is also able to alter the 
metabolism of purines, reducing the availability of substrate for xanthine oxidase (XO) in the trained muscle and plasma content of hypoxanthine and uric acid.

\section{Exercise and oxidative stress in T2DM}

Oxidative stress has often been implicated in the pathogenesis of micro and macrovascular diseases observed in diabetic individuals. Some data support a role of regular exercise in reducing lipid peroxidation. Indeed, if regular exercise can show a protective effect against oxidative stress in individuals with diabetes mellitus, their use, as a non-pharmacological therapeutic measure for T2DM, become even more attractive

The cardiovascular adaptations observed by practicing regular physical exercise (training) include, as above mentioned, not only lowering blood pressure, but also aggregation and adhesiveness of platelets and increment of cardiac blood flow [75,76]. These adaptations may be mediated, at least in part, by a hyper-regulation of basal nitric oxide (NO) production. Consistent with this idea are the reports of increased $\mathrm{NO}$ production in subjects who practiced chronic exercise, coincident with decrease in blood pressure and platelet activation [77]. The augment of NO production observed during acute exercise is able to induce protective adaptations by interaction with various transcription factors and, thereby, influence gene expression of antioxidant enzymes [78].

Although antioxidant properties have been attributed to acid uric, high level of uric acid is strongly associated, and in many cases predicts, development of hypertension, visceral obesity, insulin resistance, dyslipidaemia, T2DM, kidney disease, and cardiovascular events $[79,80]$. Several studies suggest that, under certain concentrations, uric acid might have antioxidant activity, preventing lipid peroxidation; nevertheless, its association with chronic disease highlights the uric acid oxidant-antioxidant paradox [81]. Ideally, exercise training should be able to reduce pro-inflammatory levels of uric acid to anti-oxidant and protective levels. Considering the negative consequences associated with oxidative stress, our group demonstrates in diabetic ZDF animals submitted to a swimming training protocol an increased antioxidant enzyme activity, with concomitant decline in oxidative aggression [34]. This effect of training might suggests a beneficial regulation of XO activity, which might be viewed as a possible therapeutic strategy for treatment diabetes-associated diseases [80].

In our animal studies, using the ZDF rat, the exerciseinduced oxidative injury decrease was accompanied by an augmentation in serum total antioxidant status (TAS) and in superoxide dismutase (SOD) activity (Figure 1), reinforcing the antioxidant action of training. Furthermore, the decline observed in 3-nitrotyrosine (3-NT) serum levels of trained diabetic rats suggests a decrease in peroxynitrite contents, corroborating the work of Fukai et al. (2000), which demonstrated that training promotes the increase of endothelial nitric oxide syntase (eNOS) gene expression and its phosphorylation, thus protecting endothelial cells [82].

\section{Exercise (training), inflammation and T2DM \\ Exercise and inflammation - pathophysiological aspects}

According to Kasapis et al. (2005), a single session of exercise triggers an increase in pro-inflammatory cytokines release, associated with leukocytosis and increased plasma concentration of C-reactive protein (CRP) [83]. This pro-inflammatory response to acute exercise is accompanied by a sudden increase in oxidative stress and, followed by adaptive mechanisms against inflammation [84]. Moreover, longitudinal studies showed that regular training induces a reduction in CRP levels, suggesting an inflammatory action, viewed in several conditions, such as T2DM, insulin resistance and other cardiovascular/cardiometabolic diseases [84]. Regular exercise is associated with a decrease of CRP, IL- 6 and TNF- $\alpha$ levels and, simultaneously, with increase of antiinflammatory substances, such as IL-4 and IL-10 [84], reinforcing the anti-inflammatory nature of exercise $[85,86]$.

Cytokines are released not only from mononuclear cells but also from muscle cells. Starkie et al. (2003) showed that physical exercise directly inhibits endotoxin-induced TNF- $\alpha$ production in humans, most likely through IL-6 release from exercising muscle [87]. Typically, IL-6 is the first cytokine present in circulation after exercise practice, followed by an increase in IL-1ra and IL-10 [88]. The ubiquitous role of IL-6 and the hypothesis of an exercise-induced anti-inflammatory IL6 release was recently reviewed $[89,90]$. Therefore, IL-6, a multifactorial cytokine, regulates cellular and humoral responses and plays a pivotal role in inflammation, being associated with several pathological conditions, including type 2 diabetes, emerging as an independent early predictor for T2DM and as a marker of low-grade inflammation $[89,90]$. However, what is even more interesting concerning IL-6, as Fisman and Tenenbaum (2010) recently commented, is the putative beneficial effects played as an anti-inflammatory factor, which is particularly evident in insulin sensitivity during exercise [89]. Therefore, a marked increase in circulating levels of IL-6 after exercise without muscle damage has been a remarkably consistent finding. The magnitude by which plasma IL-6 increases is related to exercise duration, intensity of effort, muscle mass involved in the mechanical work and endurance capacity [91]. The release by muscle of a humoral factor into the circulation after exercise improves insulin sensitivity, most probably through AMPK [89]. IL-6 has been indicated as the 

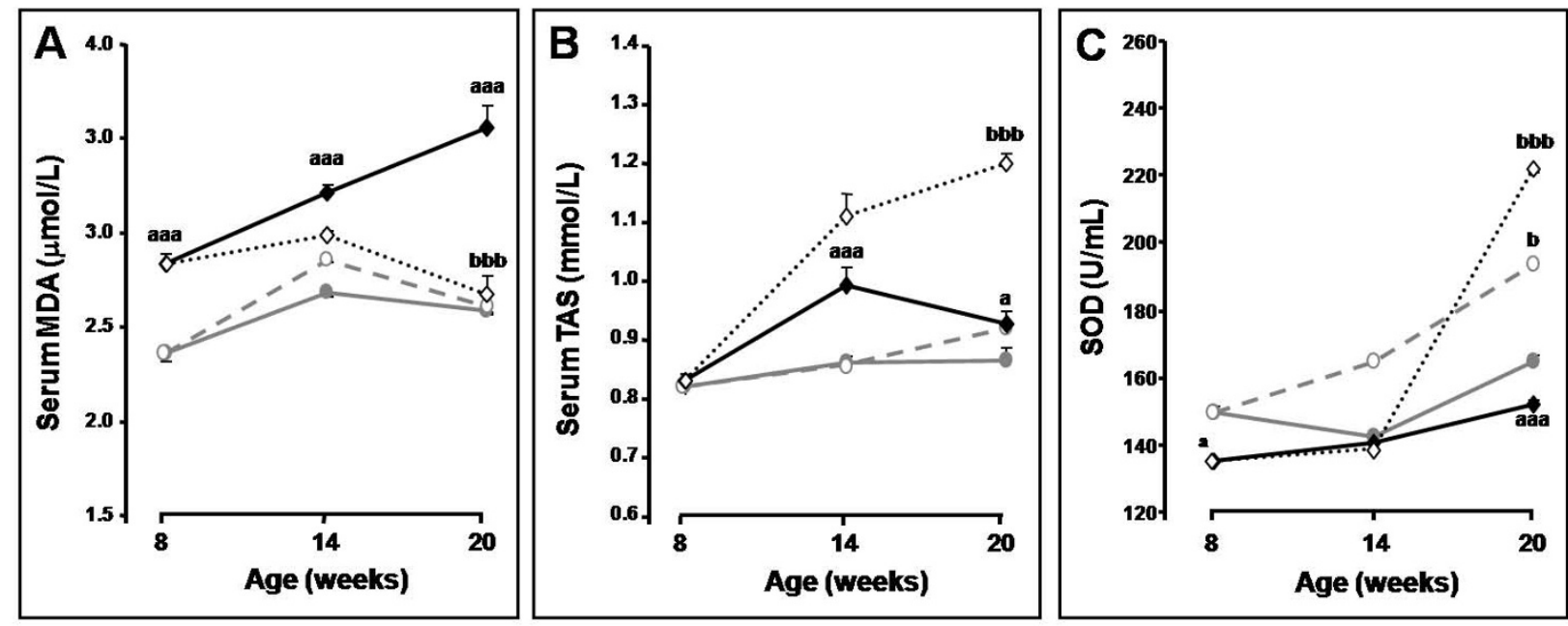

Figure 1 Evolution of serum MDA (A), TAS (B) and blood SOD (C) levels between T0 and Tf in control (+/+) and diabetic (fa/fa) Zucker diabetic fatty rats: control sedentary (black circles), control exercised (white circles), diabetic sedentary (black diamonds) and diabetic exercised (white diamonds). Data are means \pm sem of eight separate values (rats) per group. Statistical significance: aaa $P<0.05$ : sedentary diabetic vs sedentary control; ${ }^{b} \mathrm{P}<0.05$ and ${ }^{\mathrm{bbb}} \mathrm{P}<0.001$ : exercised control or diabetic vs sedentary control or diabetic, respectively. MDA, malondialdehyde; SOD, superoxide dismutase; TAS, total antioxidant status. Adapted from [32].

strongest candidate for the humoral factor released after exercise, working in a hormone-like fashion, in which it is released by the muscle, now viewed as an endocrine organ, for influencing other organs [89]. Although this hypothesis deserve further clarification, the role of IL-6 as both the "good" and the "bad", depending on the circumstances, as commented by Fisman and Tenenbaum (2010), opens new windows on the way interleukins act, and in particular concerning the effects of exercise in insulin resistance and diabetes. In this anti-inflammatory environment, IL- 6 inhibits TNF- $\alpha$ production, which was confirmed by studies in animals [92]. Furthermore, exercise also suppresses secretion of TNF- $\alpha$ by pathways independent of IL- 6 , as shown by the results obtained with knockout mice for IL-6 submitted to exercise [93]. The anti-inflammatory nature of regular exercise (training) has been associated to a reduced cardiovascular disease, particularly due the training-evoked increased expression of antioxidant and anti-inflammatory mediators in the vascular wall, which could directly inhibit atherosclerosis development [94].

The information now available concerning the effects of physical exercise on adiponectin levels is scarce and divergent [95]. There were several studies that showed that chronic exercise (programs of 6 weeks to 6 months) did not induced changes in adiponectin levels [96]. Kriketos et al. (2004) also reported, after 2-3 sessions of moderate exercise, a remarkable increase in adiponectin levels (260\%), that remaining elevated for 10 weeks, without body weight modifications [97]. The systematic review performed by Simpson and Singh (2008), considering literature searches databases conducted from ten years and including 8 randomized controlled trials, concluded that exercise of varying prescription increase serum adiponectin in $38 \%$ of de trials, demonstrating small-to-moderate effect sizes [95]. Nevertheless, the same study showed inconsistent data in the literature for increasing adiponectin levels after short-term exposure to robust aerobic or resistance training of moderate-to-high intensities, reinforcing the need of more studies reporting consistent findings concerning a clear relationship between changes in adiponectin contents and exercise mode, intensity and frequency [95].

\section{Exercise and inflammation in T2DM}

The above data highlighted the idea that beneficial effect of exercise seem to be related to its ability to decrease inflammatory cytokines levels and/or increase antiinflammatory ones, which might be also true for pathological conditions, such as type 2 diabetes.

The results from the studies of Teixeira de Lemos et al., above mentioned [33,34], clearly demonstrated the anti-inflammatory capacity of swimming exercise training in the ZDF rat, a model of obese T2DM. Actually, training was able to prevent the increase of pro-inflammatory cytokines and CRP observed in the diabetic rats. Those findings were in the line of those of Martin-Cordero et al. (2009), which found that obese Zucker rats, a model of metabolic syndrome, presents impairment of pro-inflammatory cytokines (TNF- $\alpha$, IL-6, IL-1beta and 
interferon gamma: IFN- $\gamma$ ) release by macrophages, an effect that was improved by habitual physical activity $[98,99]$. Furthermore, Teixeira de Lemos et al. also found an increment of serum adiponectin in trained obese diabetic ZDF (fa/fa) rats to levels nearby those found in the control lean rats (Figure 2). Adiponectin anti-inflammatory actions has been associated with improvement of cardiometabolic profile, which might be due, at least in part, by regulatory actions on other factors, including on TNF- $\alpha$, IL- 6 and CRP levels [100], which was also demonstrated in our study using the ZDF rat submitted to swimming regular exercise training $[33,34]$ (Figure 2). Considering that adiponectin measure was performed 48 hours after the last training session, the results may suggest an extension of the anti-inflammatory effect obtained by a single bout of exercise.
Pancreatic islets from type 2 diabetic patients present amyloid deposits, fibrosis and increased cell death, which are associated with the inflammatory response [101]. T2DM is also characterized by hyperglycemia, dyslipidaemia, increased circulating inflammatory factors and cellular stress, which are critical in precipitating islet inflammation in vivo. Chronic exposure of $\beta$ cell to these mediators induces excessive production of ROS and activation of caspases, which inhibit insulin secretion and promote apoptosis of pancreatic $\beta$ cells [102]. The impact of islet-derived inflammatory factors and islet inflammation on $\beta$-cell function and mass may be both beneficial and/or deleterious. Depending on their roles in regulating pancreatic $\beta$-cell function, some cytokines are protective while others can be detrimental. Actually, chronic exposure of islets to IL-1 $\beta$, IFN- $\gamma$, TNF- $\alpha$ and resistin inhibits insulin secretion and
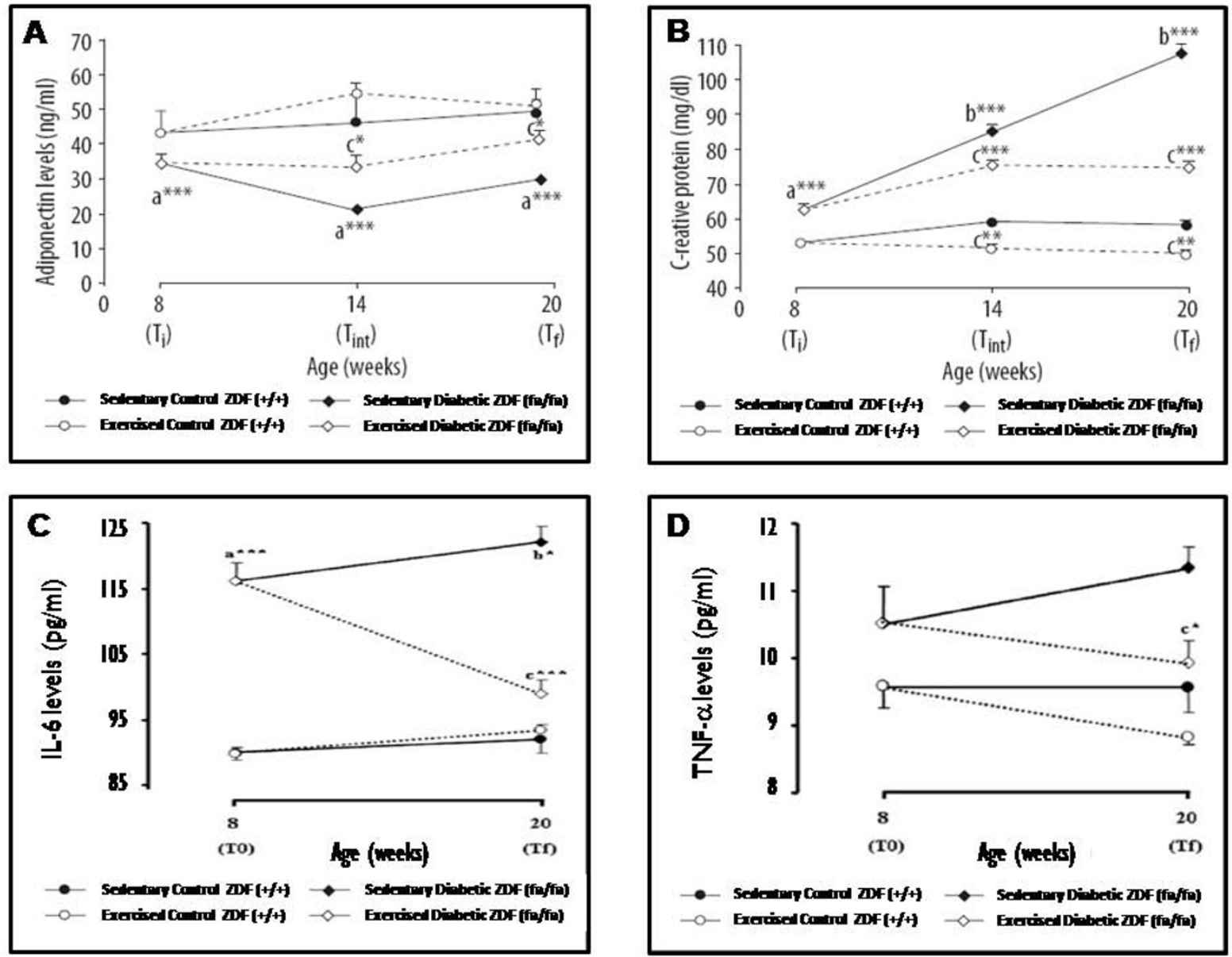

Figure 2 Evolution of serum adiponectin (A), C-reactive protein (B), IL-6 (C) and TNF- $\alpha$ (D) levels between T0 and Tf in control (+/+) and diabetic ( $\mathrm{fa} / \mathrm{fa}$ ) Zucker diabetic fatty rats: control sedentary (black circles), control exercised (white circles), diabetic sedentary (black diamonds) and diabetic exercised (white diamonds). Data are means \pm sem of eight separate values (rats) per group. Statistical significance: ${ }^{a} \mathrm{fa} / \mathrm{fa}$ versus $+/+{ }^{\circ}{ }^{\mathrm{b}}$ Tf versus T0; ${ }^{c}$ exercised rats versus sedentary rats; ${ }^{*} P<0.05$, ${ }^{* *} P<0.01$ and ${ }^{* * *} P<0.001$. IL-6, interleukin 6; T0, initial time; Tf, final time; TNF- $\alpha$, tumor necrosis factor- $\alpha$. Adapted from [[33] and [[34]]. 
induces $\beta$ cells apoptosis. Other cytokines, such as adiponectin and visfatin, exert protective effects on pancreatic $\beta$ cell function. In addition to circulating cytokines, islets also produce a variety of cytokines in response to physiologic and pathologic stimuli, and these locally produced cytokines play important roles in regulation of pancreatic $\beta$-cell function as well [103]. To maintain the normal pancreatic $\beta$-cell function, the deleterious and protective cytokines need to be balanced. The abnormal control of cytokine profile in islets and in plasma is associated with pancreatic $\beta$-cell dysfunction and type 2 diabetes [103]. All those emerging evidences reinforce the paradigm that islet inflammation is involved in the regulation of $\beta$-cell function and survival in T2DM.

Few studies have previously reported the putative beneficial effects of regular exercise practice (training) on pancreas, per se. Studies in Otsuka Long Evans Tokushima Fatty (OLETF), Goto-Kakizaki (GK), Zucker fatty (ZF) and ZDF rats have shown improvements in wholebody insulin sensitivity and preservation of $\beta$-cell mass with exercise training $[104,105]$. Insulin sensitivity improvements by exercise may confer an indirect beneficial effect on $\beta$-cells by decreasing insulin demand and minimizing $\beta$-cell exhaustion, at the same time minimizing hyperglycemia mediated loss in $\beta$-cell function [106], but a direct effect on pancreatic function could not be excluded. Although almost all the studies have demonstrated $\beta$-cell mass preservation with exercise training, none of them focus on inflammation. The recognition that islet inflammation is a key factor in TD2M pathogenesis has highlighted the concern regarding the protection of pancreatic islets and endocrine function. Thus, restoring the normal cytokine profile in endocrine pancreas and plasma may hold great promise for more efficient $\beta$-cell dysfunction treatment and T2DM management. Teixeira de Lemos et al. [34] demonstrated, using the above mentioned animal model of obese T2DM, the ZDF rat, that exercise training was able to prevent accumulation of pro-inflammatory cytokines (IL-6 and TNF- $\alpha$ ) on endocrine pancreas (Figure 3). A decrease in pancreas immunostaining of both cytokines was observed, suggesting a protective effect of regular physical exercise against local inflammation.

\section{Final remarks and conclusions}

The recognition that a tight glycaemic control significantly reduces the microvascular and macrovascular complications in T2DM indicates hyperglycaemia as the main goal of treatment. Indeed, the reduction in HbA1c values was shown to have a positive impact on cardiovascular complications associated with diabetes. Epidemiological data from the UKPDS (United Kingdom
Prospective Diabetes Study) suggest that the reduction of blood glucose decreases the risk of cardiovascular disease, which was supported by recent meta-analyses that concluded by a beneficial impact of glycaemic control in reducing events of non-fatal myocardial infarction and events of coronary heart disease, despite no significant effect on all-cause mortality $[107,108]$. Thus, nevertheless the key role of hyperglycaemia lowering in T2DM management and prevention of its serious complications, the correction of other associated risk factors, such as dyslipidaemia, hypertension, hypercoagulability, obesity and insulin resistance, is also crucial for better efficacy of treatment.

The current therapeutic arsenal for treatment of T2D is mainly based on:

i) - reduce hepatic glucose production (metformin);

ii) - stimulate insulin secretion (sulfonylureas, glinides);

iii) - delay the intestinal glucose absorption (alphaglucosidase inhibitors);

iv) - increase sensitivity of muscle, fat and liver to insulin (Thiazolidinediones);

v) - suppress glucagon secretion and delay gastric emptying [Glucagon-like peptide-1 (GLP-1) agonists];

vi) - extend GLP-1 activity after meals in order to reverse the failure of pancreatic beta cells [Dipeptidyl peptidase-4. (DPP-4) Inhibitors];

vii) - stimulate peripheral glucose uptake and decrease hepatic glucose production (insulin).

In addition, for the correction of other risk factors encountered in T2DM patients, other drugs are also requested:

i) - lipid lowering drugs (statins, ezetimibe, fibrates or combinations);

ii) - antihypertensive drugs [ACE inhibitors, angiotensin II receptor antagonists (ARAs), beta blockers, diuretics, calcium entry blockers];

iii) - antiplatelet drugs [acetylsalicylic acid (ASA), clopidogel, triflusal or associations].

A recent proposal to condense into a single drug more active principles (polypill), as a tool for primary and secondary prevention of cardiovascular disease and T2DM evolution, is, in theory, apparently very attractive. However, apart from the putative side effects and the so large range of possible drug-to-drug interactions, an antidiabetic polypill will need to be adapted to one or more stages of diabetic dysmetabolism, which is a progressive disease. The large size of formulations, as well 


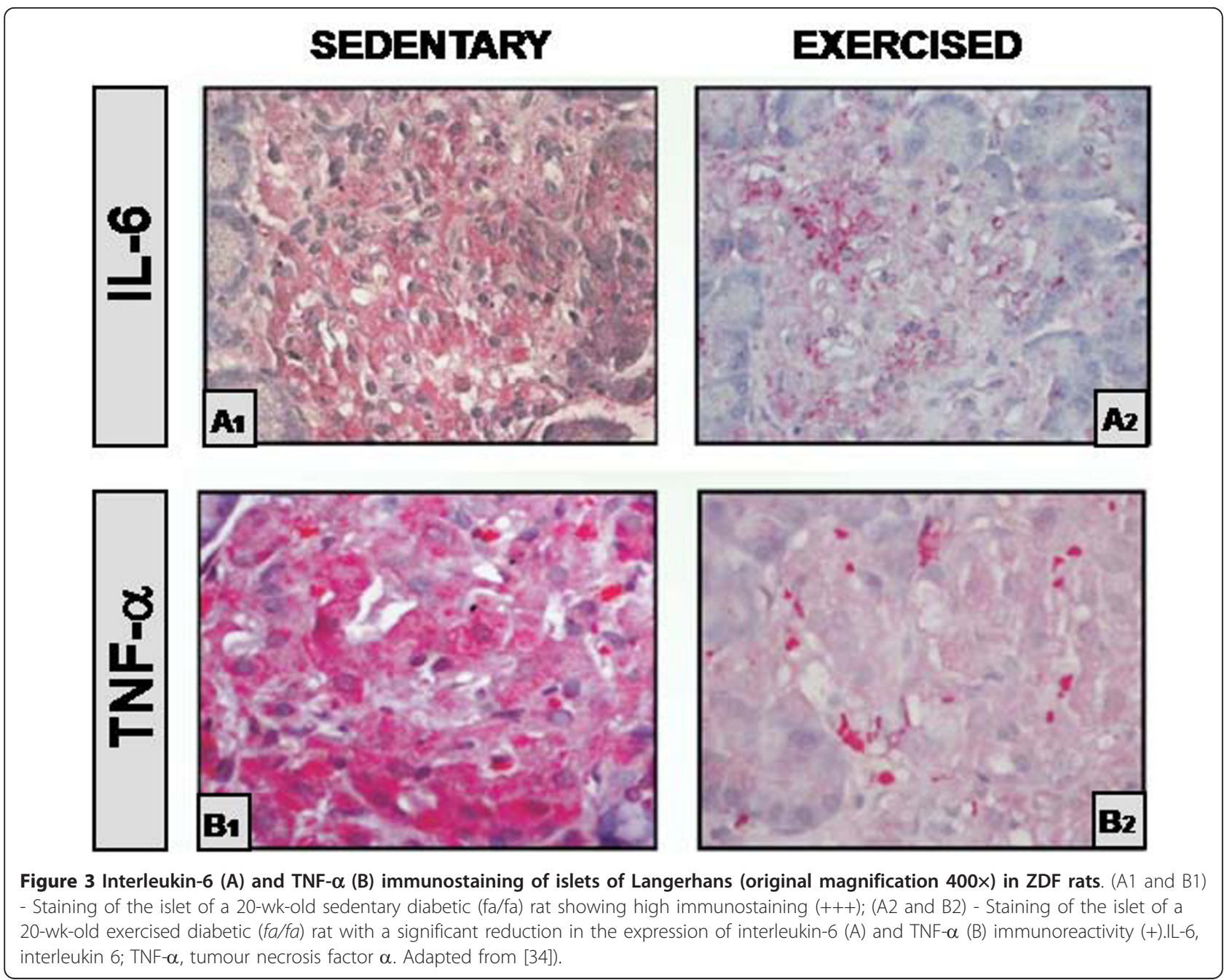

as the loss of flexibility of the therapy, which is essential for controlling metabolic changes and to handle variations in blood pressure, should be also be carefully considered.

Throughout this document, which reviewed the beneficial effects of regular exercise on the correction of risk factors for T2DM, the similarities between the effects of chronic exercise and a putative antidiabetic polypill were highlighted, with the additional advantage that exercise, when practiced regularly and under moderate intensity (training), do not causes relevant side effects and presents a greater metabolic effectiveness if compared with an antidiabetic polypill (Figure 4).

The studies developed by our group [32-34], using an animal model of obese T2DM, clearly demonstrated that the practice of a regular and moderate intensity swimming protocol (training), although unable to fully reverse pancreas lesions, has prevented and/or delayed the worsening of diabetic dysmetabolism. The obtained results highlighted the pleiotropic effect of exercise training, viewed by several properties, including:

i) - improvement of arterial vascular compliance and blood pressure;

ii) - correction of dysglycaemia and dyslipidaemia;

iii) - increment of antioxidant defenses, thus promoting a reduction of oxidative aggression;

iv) - decrease of pro-inflammatory profile and increased anti-inflammatory markers;

v) - reduced pancreatic dysfunction in Langerhans islets, responsible for the cell failure and appearance of relative insulin deficiency with insulin resistance, a feature of advanced stages of T2DM.

The cardiometabolic protective role of exercise training in T2DM becomes more clear when considering the pleiotropic actions encountered by our group, which were corroborated by other studies in animal models, as 


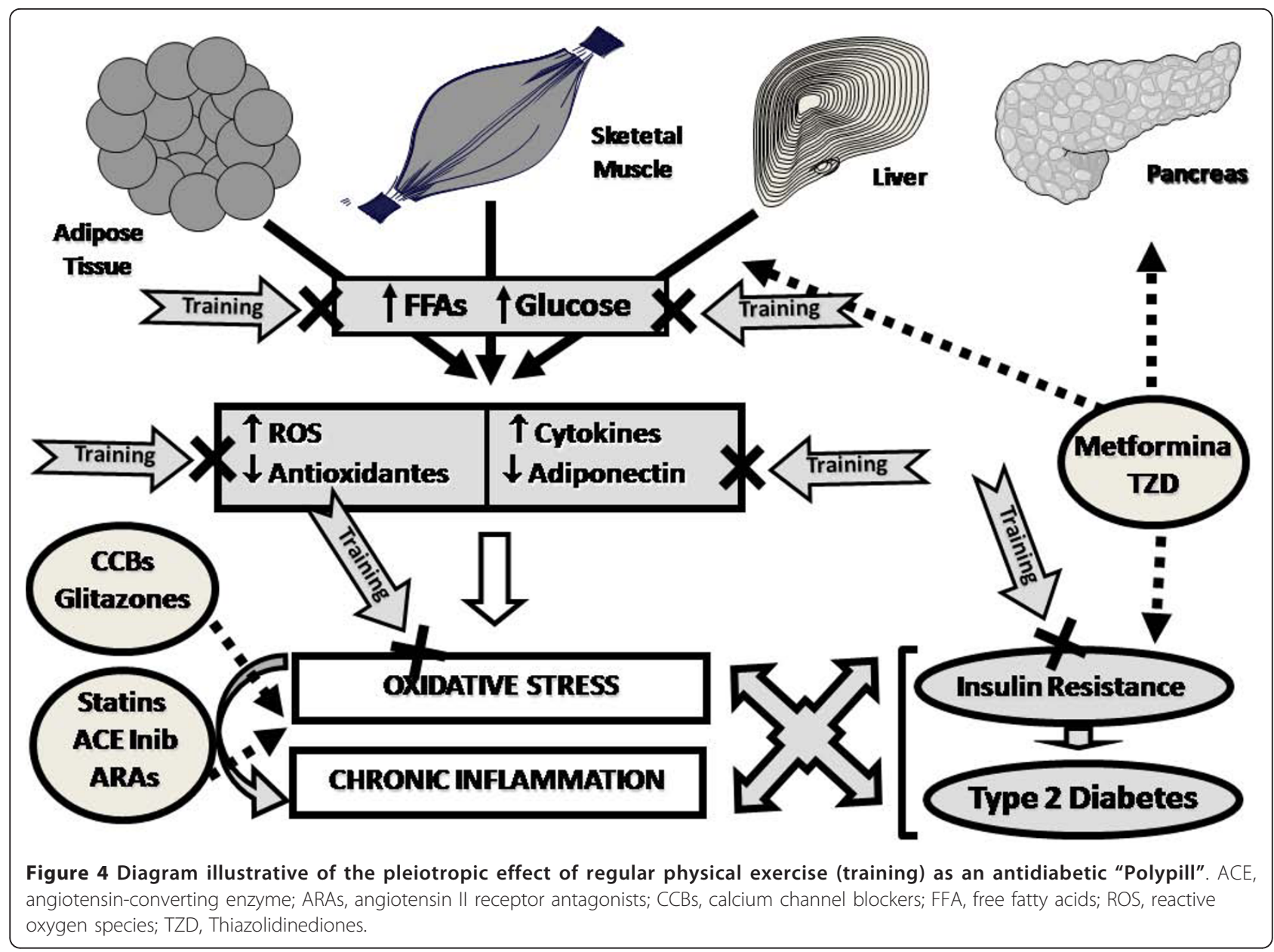

well as in humans, as above commented in detail, together with other important action that undoubtedly contribute to prevent or attenuate diabetes evolution and its complications, which includes:

- accentuation of the reduced myocardial $\beta$-adrenergic responsiveness in diabetic rats, mainly due to the reduction in $\beta 2$-adrenoceptors expression, which might have protective action [109];

- decreases in resting systolic blood pressure and 24hour proteinuria in obese diabetic patients with chronic kidney disease (CKD), which is in favour of reduced cardiovascular complications in these patients [110];

- reduction in plasma endothelin 1 (ET-1) and NO content, together with beneficial effects on anthropometric measurements and plasma oxidant stress markers, suggesting an improvement of endothelial dysfunction in patients with IGT [111];

- improvement of TNF- $\alpha$ and IL-6 release impairment by non-infiltrated peritoneal macrophages in a rat model of obese metabolic syndrome $[98,99]$.
Considering the data now reviewed, exercise prescription might be recommended as adjuvant of drug therapy for treatment/attenuation of T2DM and its serious complications, which is in line with the recommendations of American diabetes Association (ADA) and European Association for the Study of Diabetes (EASD) algorithm for the management of type 2 diabetes, further strengthened by a possible reduction in the dose of anti-diabetic drugs, as well as of other drugs used to correct/attenuate the associated cardiometabolic risk factors. This data is even more relevant when recognizing that the epidemic of obesity and insulin resistance is already focused on children and adolescents. However, we must recognize that further research is needed, namely in humans, in order to establish the preferred type, duration and intensity of training that should be practiced in order to maximize the benefits of exercise for different subgroups of T2DM patients.

List of Abbreviations

3-NT: 3-nitrotyrosine; ACE: angiotensin-converting enzyme; ADA: American Diabetes Association; AGE: advanced glycation endproducts; AMPK: 5' 
adenosine monophosphate-activated protein kinase; ARAs: angiotensin II receptor antagonists; ASA: acetylsalicylic acid; ASP: acylation-stimulating protein; BMl: body mass index; CCBs: calcium channel blockers; CKD: chronic kidney disease; CRP: C -reactive protein; DNA: deoxyribonucleic acid; DPP-4: dipeptidyl peptidase-4; EASD: European Association for the Study of Diabetes; eNOS: endothelial nitric oxide syntase; ET-1: endothelin 1; FFA: free fatty acids; GK: Goto-Kakizaki; GLP-1: glucagon-like peptide-1; GLUT4: glucose transporter type 4; HbA1c: glycosylated haemoglobin; HDL: high-density lipoprotein; HL: hepatic lipase; HOMA: homeostasis model assessment; IDF: international Diabetes Federation; IFN- $\gamma$ : interferon gamma; IGT: impaired glucose tolerance; IL: interleukin; IR: insulin resistance; IRS-1: insulin receptor substrate-1; JNK/SAPK: kinases JunNH2-terminal/kinases of proteins activated by stress; LCAT: lecithin-cholesterol acyltransferase; LPL: lipoprotein lipase; MDA: malondialdehyde; NADPH: nicotinamide adenine dinucleotide phosphate; NF-kB: nuclear factor-kB; NO: nitric oxide; OLETF: Otsuka Long Evans Tokushima Fatty; ox-LDL: oxidized low density lipoproteins; p38MAPK: mitogen-activated protein kinase p38; PAI-1: plasminogen activator inhibitor 1; PI3K: phosphatidylinositol 3-kinase; PKC: protein kinase C; PPAR-a: peroxisome proliferators activated receptor alpha; RAGE: related to receptor for AGE; ROS: reactive oxygen species; SOD: superoxide dismutase; T2DM: type 2 diabetes mellitus; TAS: total antioxidant status; T-Chol: totalcholesterol; TGs: triglycerides; TNF-a: tumour necrosis factor a; TZD: Thiazolidinediones; UKPDS: United Kingdom Prospective Diabetes Study; VEGF: vascular endothelial growth factor; XO: xanthine oxidase; ZDF: Zucker Diabetic Fatty; ZF: Zucker fatty

\section{Authors' contributions}

ETL, SN and FR drafted the manuscript. FT and FR critically reviewed the manuscript. All authors read and approved the final manuscript.

\section{Competing interests}

The authors declare that they have no competing interests.

Received: 19 January 2011 Accepted: 28 January 2011

Published: 28 January 2011

\section{References}

1. International Diabetes Federation: Diabetes: a global threat. Diabetes Atlas. 3 edition. Brussels; 2008, 1-15[http://www.eatlas.idf.org/index1397.html].

2. Gaede PH, Jepsen PV, Larsen JN, Jensen GV, Parving HH, Pedersen OB: The Steno-2 study. Intensive multifactorial intervention reduces the occurrence of cardiovascular disease in patients with type 2 diabetes. Ugeskr Laeger 2003, 165(26):2658-2661.

3. Hu FB: Sedentary lifestyle and risk of obesity and type 2 diabetes. Lipids 2003, 38(2):103-108.

4. Carvalhal MM, Padez MC, Moreira PA, Rosado VM: Overweight and obesity related to activities in Portuguese children, 7-9 years. Eur J Public Health 2007, 17(1):42-46.

5. Li G, Zhang P, Wang J, Gregg EW, Yang W, Gong Q, Li H, Li H, Jiang Y, An Y, Shuai Y, Zhang B, Zhang J, Thompson Tj, Gerzoff RB, Roglic G, Hu Y, Bennett PH: The long-term effect of lifestyle interventions to prevent diabetes in the China Da Qing Diabetes Prevention Study: a 20-year follow-up study. Lancet 2008, 371(9626):1783-1789.

6. Lindström J, llanne-Parikka P, Peltonen M, Aunola S, Eriksson JG, Hemiö K,


Louheranta A, Mannelin M, Paturi M, Sundvall J, Valle T, Uusitupa M, Tuomilehto J, Finnish Diabetes Prevention Study Group: Sustained reduction in the incidence of type 2 diabetes by lifestyle intervention: follow-up of the Finnish Diabetes Prevention Study. Lancet 2006, 368(9548):1673-1679.

7. Das SK, Elbein SC: The genetic basis of type 2 diabetes. Cellscience 2006, 2:100-131.

8. Stumvoll M, Goldstein BJ, van Haeften TW: Type 2 diabetes: principles of pathogenesis and therapy. Lancet 2005, 365:1333-1346.

9. Eriksson J, Lindström J, Tuomilehto J: Potential for the prevention of type 2 diabetes. Br Med Bull 2001, 60:183-199.

10. Zinman B: Type 2 diabetes mellitus: magnitude of the problem and failure to achieve glycaemic control. Endocrinol Metab Clin North Am 2006, 35:3-5.

11. Praet SF, Manders RJ, Meex RC, Lieverse AG, Stehouwer CD, Kuipers $H$, Keizer HA, van Loon LJ: Glycaemic instability is an underestimated problem in Type II diabetes. Clin Sci (Lond) 2006, 111(2):119-126.
12. Ceriello A: Postprandial hyperglycemia and diabetes complications: is it time to treat? Diabetes 2005, 54:1-7.

13. Baynes JW, Thorpe SR: Role of oxidative stress in diabetic complications: a new perspective on an old paradigm. Diabetes 1999, 48(1):1-9.

14. Evans JL, Maddux BA, Goldfine ID: The molecular basis for oxidative stressinduced insulin resistance. Antioxid Redox Signal 2005, 7(7-8):1040-1052.

15. Evans $J L$, Goldfine ID, Maddux BA, Grodsky GM: Are oxidative stressactivated signaling pathways mediators of insulin resistance and $\beta$-cell dysfunction? Diabetes 2003, 52:1-8.

16. Urakawa H, Katsuki A, Sumida Y, Gabazza EC, Murashima S, Morioka K, Maruyama N, Kitagawa N, Tanaka T, Hori Y, Nakatani K, Yano Y, Adachi Y: Oxidative stress is associated with adiposity and insulin resistance in men. J Clin Endocrinol Metab 2003, 88(10):4673-4676.

17. Robertson RP, Harmon J, Tran PO, Tanaka Y, Takahashi H: Glucose toxicity in beta-cells: type 2 diabetes, good radicals gone bad, and the glutathione connection. Diabetes 2003, 52:581-587.

18. Talior I, Yarkoni M, Bashan N, Eldar-Finkelman H: Increased glucose uptake promotes oxidative stress and PKC-delta activation in adipocytes of obese, insulin-resistant mice. Am J Physiol Endocrinol Metab 2003, 285(2):E295-E302.

19. Evans $\lrcorner$ : Antioxidants: do they have a role in the treatment of insulin resistance? Indian J Med Res 2007, 125(3):355-372.

20. Evans JL, Goldfine ID, Maddux BA, Grodsky GM: Oxidative stress and stress-activated signaling pathways: a unifying hypothesis of type 2 diabetes. Endocr Rev 2002, 23(5):599-622.

21. Yamamoto Y, Gaynor RB: Role of the NF-kappaB pathway in the pathogenesis of human disease states. Curr Mol Med 2001, 1(3):287-296.

22. Cardozo AK, Heimberg $H$, Heremens $Y$, Leeman R, Kutlu B, Kruhøffer M, Ørntoft T, Eizirik DL: A comprehensive analysis of cytokine-induced and nuclear factor-kB dependent genes in primary rat pancreatic $\beta$-cells. J Biol Chem 2001, 276:48879-48886.

23. Wellen KE, Hotamisligil GS: Obesity-induced inflammatory changes in adipose tissue. J Clin Invest 2003, 112:1785-1788.

24. Furler SM, Gan SK, Poynten AM, Chisholm DJ, Campbell LV, Kriketos AD: Relationship of adiponectin with insulin sensitivity in humans, independent of lipid availability. Obesity (Silver Spring) 2006, 14:228-234

25. Kadowaki T, Yamauchi T, Kubota N, Hara K, Ueki K, Tobe K: Adiponectin and adiponectin receptors in insulin resistance, diabetes, and the metabolic syndrome. J Clin Invest 2006, 116:1784-1792.

26. Cai W, Zhu L, Chen X, Uribarri J, Peppa M: Association of advanced glycoxidation end products and inflammation markers with thrombosis of arteriovenous grafts in hemodialysis patients. Am J Nephrol 2006, 26(2):181-185.

27. Yano Y, Gabazza EC, Kitagawa N, Bruno NE, Matsumoto K, Nakatani K, Araki R, Katsuki A, Adachi $Y$, Sumida $Y$ : Tumor necrosis factor-alpha is associated with increased protein $C$ activation in nonobese type 2 diabetic patients. Diabetes Care 2004, 27(3):844-845.

28. Maedler K, Spinas GA, Dyntar D, Moritz W, Kaiser N, Donath MY: Distinct effects of saturated and monounsaturated fatty acids on beta-cell turnover and function. Diabetes 2001, 50:69-76.

29. Cnop M, Hannaert JC, Grupping AY, Pipeleers DG: Low density lipoprotein can cause death of islet beta-cells by its cellular uptake and oxidative modification. Endocrinology 2002, 143(9):3449-3453.

30. El-Assaad W, Buteau J, Peyot ML, Nolan C, Roduit R, Hardy S, Joly E, Dbaibo G, Rosenberg L, Prentki M: Saturated fatty acids synergize with elevated glucose to cause pancreatic beta-cell death. Endocrinology 2003, 144:4154-4163.

31. Poitout $V$, Robertson RP: Minireview: secondary beta-cell failure in type 2 diabetes: a convergence of glucotoxicity and lipotoxicity. Endocrinology 2002, 143:339-342.

32. de Lemos ET, Reis F, Baptista S, Garrido AP, Pinto R, Sepodes B, Vala H, Rocha-Pereira P, Silva AS, Teixeira F: Efeitos do exercício físico aeróbio no perfil metabólico e oxidativo de ratos diabéticos tipo 2. Bull SPHM 2007, 22(1):16-28.

33. de Lemos ET, Reis F, Baptista S, Pinto R, Sepodes B, Vala H, Rocha-Pereira B, Silva AS, Teixeira F: Exercise training is associated with improved levels of C-reactive protein and adiponectin in ZDF (type 2) diabetic rats. Med Sci Monit 2007, 13(8):BR168-174.

34. Teixeira de Lemos E, Reis F, Baptista S, Pinto R, Sepodes B, Vala H, RochaPereira, da Silva GC, Teixeira N, Silva AS, Carvalho L, Teixeira F, Das UN: Exercise training decreases proinflammatory profile in Zucker diabetic (type 2) fatty rats. Nutrition 2009, 25(3):330-339. 
35. Boulé NG, Haddad E, Kenny GP, Wells GA, Sigal RJ: Effects of exercise on glycaemic control and body mass in type 2 diabetes mellitus: a metaanalysis of controlled clinical trials. JAMA 2001, 286(10):1218-1227.

36. Mourier A, Gautier JF, De Kerviler E, Bigard AX, Villette JM, Garnier JP, Duvallet A, Gurzennec CY, Cathelineau G: Mobilization of visceral adipose tissue related to the improvement in insulin sensitivity in response to physical training in NIDDM. Effects of branched-chain amino acid supplements. Diabetes Care 1997, 20(3):385-391.

37. Hansen AK, Fischer CP, Plomgaard P, Andersen JL, Saltin B, Pedersen BK: Skeletal muscle adaptation: training twice every second day vs. training once daily. J Appl Physiol 2005, 98(1):93-99.

38. Eaton MD, Hodgson DR, Evans DL, Rose RJ: Effects of low- and moderateintensity training on metabolic responses to exercise in thoroughbreds. Equine Vet J Supp/ 1999, 30:521-527.

39. Tuomilehto J, Lindström J, Eriksson JG, Valle T, Hämäläinen H, llanneParikka P, Keinänen-Kiukaanniemi S, Laakso M, Louheranta A, Rastas M, Salminen V, Uusitupa M, Finnish Diabetes Prevention Study Group: Prevention of type 2 diabetes mellitus by changes in lifestyle among subjects with impaired glucose tolerance. N Engl J Med 2001, 344(18):1343-1350.

40. Sigal RJ, Kenny GP, Boulé NG, Wells GA, Prud'homme D, Fortier M, Reid RD, Tulloch $H$, Coule $D$, Phillips $P$, Jennings $A$, Jaffey J: Effects of aerobic training, resistance training, or both on glycaemic control in type 2 diabetes: a randomized trial. Ann Intern Med 2007, 147(6):357-369.

41. Ross R, Janssen I, Dawson J, Kungl AM, Kuk JL, Wong SL, Nguyen-Duy TB, Lee S, Kilpatrick K, Hudson R: Exercise-induced reduction in obesity and insulin resistance in women: a randomized controlled trial. Obes Res 2004, 12(5):789-798.

42. Lee S, Kuk JL, Davidson LE, Hudson R, Kilpatrick K, Graham TE, Ross R: Exercise without weight loss is an effective strategy for obesity reduction in obese individuals with and without Type 2 diabetes. $J$ App/ Physiol 2005, 99(3):1220-1225.

43. Király MA, Bates HE, Kaniuk NA, Yue JT, Brumell JH, Matthews SG, Riddell MC, Vranic M: Swim training prevents hyperglycemia in ZDF rats: mechanisms involved in the partial maintenance of beta-cell function. Am J Physiol Endocrinol Metab 2008, 294(2):E271-E283.

44. Boulè NG, Haddad E, Kenny GP, Wells GA, Sigal RJ: Effects of exercise on glycemic control and body mass in type 2 diabetes mellitus: a metaanalysis of controlled clinical trials. JAMA 2001, 286:1218-1227.

45. Boulè NG, Kenny GP, Hadda E, Wells GA: Sigal RJ Meta-analysis of the effect of structured exercise training on cardiorespiratory fitness in Type 2 diabetes mellitus. Diabetologia 2003, 46:1071-1081.

46. Christ-Roberts CY, Pratipanawatr T, Pratipanawatr W, Berria R, Belfort R, Kashyap S, Mandarino LJ: Exercise training increases glycogen synthase activity and GLUT4 expression but not insulin signaling in overweight nondiabetic and type 2 diabetic subjects. Metabolism 2004, 53(9):1233-1242.

47. Wang $Y$, Simar D, Fiatarone Singh MA: Adaptations to exercise training within skeletal muscle in adults with type 2 diabetes or impaired glucose tolerance: a systematic review. Diabetes Metab Res Rev 2009, 25(1):13-40.

48. Sato Y, Nagasaki M, Nakai N, Fushimi T: Physical exercise improves glucose metabolism in lifestyle-related diseases. Exp Biol Med 2003, 228(10):1208-1212.

49. Sigal RJ, Kenny GP, Wasserman DH, Castaneda-Sceppa C: Physical activity/exercise and type 2 diabetes. Diabetes Care 2004, 27(10):2518-2539.

50. McArdle F, Spiers S, Aldemir H, Vasilaki A, Beaver A, Iwanejko L, McArdle A Jackson MJ: Preconditioning of skeletal muscle against contractioninduced damage: the role of adaptations to oxidants in mice. J Physiol 2004, 561:233-244

51. Berg A, Frey I, Baumstark MW, Halle M, Keul J: Physical activity and lipoprotein lipid disorders. Sports Med 1994, 17(1):6-21.

52. Goldhammer E, Ben-Sira D, Zaid G, Biniamini Y, Maor I, Lanir A, Sagiv M: Paraoxonase activity following exercise-based cardiac rehabilitation program. J Cardiopulm Rehabil Prev 2007, 27(3):151-154.

53. Romani R, De Medio GE, di Tullio S, Lapalombella R, Pirisinu I, Margonato V, Veicsteinas A, Marini M, Rosi G: Modulation of paraoxonase 1 and 3 expression after moderate exercise training in the rat. J Lipid Res 2009, 50(10):2036-2045.
54. Luquet S, Gaudel C, Holst D, Lopez-Soriano J, Jehi-Pietri C, Fredenrich A, Grimaldi PA: Roles of PPAR delta in lipid absorption and metabolism: a new target for the treatment of type 2 diabetes. Biochim Biophys Acta 2005, 1740(2):313-317

55. Look AHEAD Research Group, Pi-Sunyer X, Blackburn G, Brancati FL, Bray GA, Bright R, Clark JM, Curtis JM, Espeland MA, Foreyt JP, Graves K, Haffner SM, Harrison B, Hill JO, Horton ES, Jakicic J, Jeffery RW, Johnson KC, Kahn S, Kelley DE, Kitabchi AE, Knowler WC, Lewis CE, Maschak-Carey BJ, Montgomery B, Nathan DM, Patricio J, Peters A, Redmon JB, Reeves RS, Ryan DH, Safford M, Van Dorsten B, Wadden TA, Wagenknecht L, WescheThobaben J, Wing RR, Yanovski SZ: Reduction in weight and cardiovascular disease risk factors in individuals with type 2 diabetes: one-year results of the look AHEAD trial. Diabetes Care 2007, 30:1374-1383.

56. Krook A, Holm I, Pettersson S, Wallberg-Henriksson H: Reduction of risk factors following lifestyle modification programme in subjects with type 2 (non-insulin dependent) diabetes mellitus. Clin Physiol Funct Imaging 2003, 23:21-30.

57. De Feyter HM, Praet SF, van den Broek NM, Kuipers H, Stehouwer CD, Nicolay K, Prompers JJ, van Loon LJ: Exercise training improves glycemic control in long-standing insulin-treated type 2 diabetic patients. Diabetes Care 2007, 30(10):2511-2513.

58. Sigal RJ, Kenny GP, Boulé NG, Wells GA, Prud'homme D, Fortier M, Reid RD,

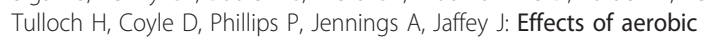
training, resistance training, or both on glycemic control in type 2 diabetes: a randomized trial. Ann Intern Med 2007, 147(6):357-369.

59. Lira FS, Yamashita AS, Uchida MC, Zanchi NE, Gualano B, Martins E Jr, Caperuto EC, Seelaender M: Low and moderate, rather than high intensity strength exercise induces benefit regarding plasma lipid profile. Diabetol Metab Syndr 2010, 2:31.

60. Winder WW, Hardie DG: Inactivation of acetyl-CoA carboxylase and activation of AMP activated protein kinase in muscle during exercise. Am J Physiol 1996, 270(2 Pt 1):E299-304.

61. Berg AH, Combs TP, Scherer PE: ACRP30/adiponectin: an adipokine regulating glucose and lipid metabolism. Trends Endocrinol Metab 2002, 13(2):84-89.

62. Pold R, Jensen LS, Jessen N, Buhl ES, Schmitz O, Flyvbjerg A, Fujii N, Goodyear LJ, Gotfredsen CF, Brand CL, Lund S: Long-term AICAR administration and exercise prevents diabetes in ZDF rats. Diabetes 2005, 54(4):928-934.

63. Whelton SP, Chin A, Xin X, He J: Effect of aerobic exercise on blood pressure: a meta-analysis of randomized, controlled trials. Ann Intern Med 2002, 136(7):493-503.

64. Chrysohoou C, Pitsavos C, Panagiotakos DB, Kokkinos PF, Stefanadis C, Toutouzas P: The association between physical activity and the development of acute coronary syndromes in treated and untreated hypertensive subjects. J Clin Hypertens 2003, 5(2):115-120.

65. Brum PC, Da Silva GJ, Moreira ED, Ida F, Negrao CE, Krieger EM: Exercise training increases baroreceptor gain sensitivity in normal and hypertensive rats. Hypertension 2000, 36(6):1018-1022.

66. Zinman B, Ruderman N, Campaigne BN, Devlin JT, Schneider SH, American Diabetes Association: Physical activity/exercise and diabetes mellitus. Diabetes Care 2003, 26(Suppl 1):S73-77.

67. Thomas DE, Elliott EJ, Naughton GA: Exercise for type 2 diabetes mellitus. Cochrane Database Syst Rev 2006, 3:CD002968.

68. Patel A, ADVANCE Collaborative Group, MacMahon S, Chalmers J, Neal B, Woodward M, Billot L, Harrap S, Poulter N, Marre M, Cooper M, Glasziou P, Grobbee DE, Hamet P, Heller S, Liu LS, Mancia G, Mogensen CE, Pan CY, Rodgers A, Williams B: Effects of a fixed combination of perindopril and indapamide on macrovascular and microvascular outcomes in patients with type 2 diabetes mellitus (the ADVANCE trial): a randomised controlled trial. Lancet 2007, 370:829-840.

69. Bloomer RJ, Goldfarb AH: Anaerobic exercise and oxidative stress: a review. Can J Appl Physiol 2004, 29(3):245-263.

70. Di Meo S, Venditti P: Mitochondria in exercise-induced oxidative stress. Biol Signals Recept 2001, 10(1-2):125-140.

71. Cooper CE, Vollaard NB, Choueiri T, Wilson MT: Exercise, free radicals and oxidative stress. Biochem Soc Trans 2002, 30(2):280-285.

72. Urso ML, Clarkson PM: Oxidative stress, exercise, and antioxidant supplementation. Toxicology 2003, 189(1-2):41-54. 
73. Sen CK: Oxidants and antioxidants in exercise. J Appl Physiol 1995, 79(3):675-686.

74. Radak Z, Sasvari M, Nyakas C, Taylor AW, Ohno H, Nakamoto H, Goto S: Regular training modulates the accumulation of reactive carbonyl derivatives in mitochondrial and cytosolic fractions of rat skeletal muscle. Arch Biochem Biophys 2000, 383(1):114-118.

75. Atalay M, Laaksonen DE: Diabetes, oxidative stress and physical exercise. J Sports Sci Med 2002, 1:1-14.

76. Gielen S, Adams V, Mobius-Winkler S, Linke A, Erbs S, Yu J, Kempf W, Schubert A, Schuler G, Hambrecht R: Anti-inflammatory effects of exercise training in the skeletal muscle of patients with chronic heart failure. J Am Coll Cardiol 2003, 42(5):861-868.

77. Fukai T, Siegfried MR, Ushio-Fukai M, Cheng Y, Kojda G, Harrison DG: Regulation of the vascular extracellular superoxide dismutase by nitric oxide and exercise training. J Clin Invest 2000, 105(11):1631-1639.

78. Leeuwenburgh C, Heinecke JW: Oxidative stress and antioxidants in exercise. Curr Med Chem 2001, 8(7):829-838.

79. Johnson RJ, Kang DH, Feig D, Kivlighn S, Kanellis, Watanabe S, Tuttle KR, Rodriguez-lturbe B, Herrera-Acosta J, Mazzali M: Is there a pathogenetic role for uric acid in hypertension and cardiovascular and renal disease? Hypertension 2003, 41:1183-1190.

80. Manzato E: Uric acid: an old actor for a new role. Intern Emerg Med 2007, 2(1):1-2.

81. Sautin $Y Y$, Johnson RJ: Uric acid: the oxidant-antioxidant paradox. Nucleosides Nucleotides Nucleic Acids 2008, 27(6):608-619.

82. Fukai T, Siegfried MR, Ushio-Fukai M, Cheng Y, Kojda G, Harrison DG: Regulation of the vascular extracellular superoxide dismutase by nitric oxide and exercise training. J Clin Invest 2000, 105(11):1631-1639.

83. Kasapis C, Thompson PD: The effects of physical activity on serum Creactive protein and inflammatory markers: a systematic review. J Am Coll Cardiol 2005, 45(10):1563-1569.

84. Fallon KE, Fallon SK, Boston T: The acute phase response and exercise: court and field sports. Br J Sports Med 2001, 35(3):170-173.

85. Das UN: Anti-inflammatory nature of exercise. Nutrition 2004, 20(3):323-326.

86. Petersen AM, Pedersen BK: The anti-inflammatory effect of exercise. J Appl Physiol 2005, 98(4):1154-1162.

87. Starkie R, Ostrowski SR, Jauffred S, Febbraio M, Pedersen BK: Exercise and IL-6 infusion inhibit endotoxin-induced TNF-alpha production in humans. FASEB J 2003, 17:884-886.

88. Pedersen BK, Febbraio MA: Muscle as an endocrine organ: focus on muscle-derived interleukin-6. Physiol Rev 2008, 88:1379-1406.

89. Fisman EZ, Tenenbaum A: The ubiquitous interleukin-6: a time for Reappraisal. Cardiovasc Diabetol 2010, 9:62.

90. Pedersen BK: IL-6 signalling in exercise and disease. Biochemical Society Transactions 2007, 35:1295-1297.

91. Febbraio MA, Pedersen BK: Muscle-derived interleukin-6: mechanisms for activation and possible biological roles. FASEB J 2002, 16(11):1335-1347.

92. Matthys P, Mitera T, Heremans H, Van Damme J, Billiau A: Anti-gamma interferon and anti-interleukin- 6 antibodies affect staphylococcal enterotoxin B-induced weight loss, hypoglycemia, and cytokine release in D- physique anxiety in older adults: fitness and efficacy influences. Aging Ment Health 2002, 6(3):222-230.

93. Keller C, Keller P, Giralt M, Hidalgo J, Pedersen BK: Exercise normalises overexpression of TNF-alpha in knockout mice. Biochem Biophys Res Commun 2004, 321(1):179-182.

94. Wilund KR: Is the anti-inflammatory effect of regular exercise responsible for reduced cardiovascular disease? Clin Sci (Lond) 2007, 112(11):543-55.

95. Simpson KA, Singh MA: Effects of exercise on adiponectin: a systematic review. Obesity (Silver Spring) 2008, 16(2):241-256.

96. Yatagai T, Nishida Y, Nagasaka S, Nakamura T, Tokuyama K, Shindo M, Tanaka H, Ishibashi S: Relationship between exercise training-induced increase in insulin sensitivity and adiponectinemia in healthy men. Endocr J 2003, 50(2):233-238.

97. Kriketos AD, Gan SK, Poynten AM, Furler SM, Chisholm DJ, Campbell LV: Exercise increases adiponectin levels and insulin sensitivity in humans. Diabetes Care 2004, 27(2):629-630.

98. Martin-Cordero L, Garcia JJ, Giraldo E, De la Fuente M, Manso R, Ortega E: Influence of exercise on the circulating levels and macrophage production of IL-1beta and IFN gamma affected by metabolic syndrome: an obese Zucker rat experimental animal model. Eur J Appl Physiol 2009, 107(5):535-543.

99. Martín-Cordero L, García JJ, Hinchado MD, Bote E, Manso R, Ortega E: Habitual physical exercise improves macrophage IL- 6 and TNF- $a$ deregulated release in the obese Zucker rat model of the metabolic syndrome. Neuroimmunomodulation 2011, 18(2):123-130.

100. Ravin KR, Kamari Y, Navni I, Grossman E, Sharabi Y: Adiponectin: Linking the metabolic syndrome to its cardiovascular consequences. Expert Rev Cardiovasc Ther 2005, 3:465-471.

101. Hull RL, Westermark GT, Westermark P, Kahn SE: Islet amyloid: a critical entity in the pathogenesis of type 2 diabetes. J Clin Endocrinol Metab 2004, 89:3629-3643.

102. Andersson AK, Flodström M, Sandler S: Cytokine-induced inhibition of insulin release from mouse pancreatic $\beta$-cells deficient in inducible nitric oxide synthase. Biochem Biophys Res Commun 2001, 281(2):396-403.

103. Donath MY, Böni-Schnetzler M, Ellingsgaard $H$, Halban PA, Ehses JA: Cytokine production by islets in health and diabetes: cellular origin, regulation and function. Trends in Endocrinol Metab 2010, 21(5):261-267.

104. Minato K, Shiroya $Y$, Nakae $Y$, Kondo T: The effect of chronic exercise on the rat pancreas. Int J Pancreatol 2000, 27(2):151-156.

105. Shima K, Zhu M, Noma Y, Mizuno A, Murakami T, Sano T, Kuwajima M: Exercise training in Otsuka Long-Evans Tokushima Fatty rat, a model of spontaneous non-insulin-dependent diabetes mellitus: effects on the Bcell mass, insulin content and fibrosis in the pancreas. Diabetes Res Clin Pract 1997, 35(1):11-19.

106. Dela F, von Linstow ME, Mikines KJ, Galbo H: Physical training may enhance beta-cell function in type 2 diabetes. Am J Physiol Endocrinol Metab 2004, 287(5):E1024-1031.

107. Marso SP, Kennedy KF, House JA, McGuire DK: The effect of intensive glucose control on all-cause and cardiovascular mortality, myocardial infarction and stroke in persons with type 2 diabetes mellitus: a systematic review and meta-analysis. Diab Vasc Dis Res 2010, 7(2):119-130.

108. Ray KK, Seshasai SR, Wijesuriya S, Sivakumaran R, Nethercott S, Preiss D, Erqou S, Sattar N: Effect of intensive control of glucose on cardiovascular outcomes and death in patients with diabetes mellitus: a meta-analysis of randomised controlled trials. Lancet 2009, 373(9677):1765-1772.

109. Lahaye SD, Gratas-Delamarche A, Malardé L, Vincent S, Zguira MS, Morel SL, Delamarche $\mathrm{P}$, Zouhal H, Carré F, Bekono FR: Intense exercise training induces adaptation in expression and responsiveness of cardiac badrenoceptors in diabetic rats. Cardiovasc Diabetol 2010, 9:72.

110. Leehey DJ, Moinuddin I, Bast JP, Qureshi S, Jelinek CS, Cooper C, Edwards LC, Smith BM, Collins EG: Aerobic exercise in obese diabetic patients with chronic kidney disease: a randomized and controlled pilot study. Cardiovasc Diabetol 2009, 8:62.

111. Kasımay O, Ergen N, Bilsel S, Kaçar O, Deyneli O, Gogas D, Akalın S, Yeğen $\mathrm{BÇ,} \mathrm{Kurtel} \mathrm{H:} \mathrm{Diet-supported} \mathrm{aerobic} \mathrm{exercise} \mathrm{reduces} \mathrm{blood}$ endothelin-1 and nitric oxide levels in individuals with impaired glucose tolerance. J Clin Lipidol 2010, 4(5):427-434.

doi:10.1186/1475-2840-10-12

Cite this article as: Teixeira-Lemos et al:: Regular physical exercise training assists in preventing type 2 diabetes development: focus on its antioxidant and anti-inflammatory properties. Cardiovascular Diabetology 2011 10:12

\section{Submit your next manuscript to BioMed Central and take full advantage of:}

- Convenient online submission

- Thorough peer review

- No space constraints or color figure charges

- Immediate publication on acceptance

- Inclusion in PubMed, CAS, Scopus and Google Scholar

- Research which is freely available for redistribution

Submit your manuscript at www.biomedcentral.com/submit
C Biomed Central 